\title{
Risk Analysis and Reliability Assessment of Overhead Cranes Using Fault Tree Analysis Integrated with Markov Chain and Fuzzy Bayesian Networks
}

\author{
Heidar Mohammadi, ${ }^{1}$ Zohreh Fazli, ${ }^{2}$ Hiro Kaleh, ${ }^{3}$ Hamid Reza Azimi, ${ }^{3}$ \\ Saber Moradi Hanifi $\left(\mathbb{D},{ }^{3}\right.$ and Nasrin Shafiee ${ }^{4,5}$ \\ ${ }^{1}$ Department of Occupational Health and Safety, School of Health, Larestan University of Medical Sciences, \\ Larestan, Iran \\ ${ }^{2}$ Department of Occupational Health Engineering, School of Public Health, Bam University of Medical Sciences, Bam, Iran \\ ${ }^{3}$ Department of Occupational Health Engineering, School of Public Health and Safety, \\ Shahid Beheshti University of Medical Sciences, Tehran, Iran \\ ${ }^{4}$ Vali-Asr Hospital, Bafgh, Iran \\ ${ }^{5}$ Yazd University of Medical Sciences, Yazd, Iran
}

Correspondence should be addressed to Saber Moradi Hanifi; sabermoradi22@yahoo.com

Received 10 June 2021; Revised 28 August 2021; Accepted 14 September 2021; Published 12 October 2021

Academic Editor: Harish Garg

Copyright (c) 2021 Heidar Mohammadi et al. This is an open access article distributed under the Creative Commons Attribution License, which permits unrestricted use, distribution, and reproduction in any medium, provided the original work is properly cited.

\begin{abstract}
Establishing an adequate level of reliability in the overhead crane operations is an important and vital principle to avoid undesirable consequences. To do this, it is appropriate to have a comprehensive approach for risk and reliability assessment of the most probable failure scenarios during overhead crane operations. In this study, fault tree analysis (FTA) in combination with fuzzy set theory, Bayesian network (BN), and Markov chain was used to evaluate the probability of top event and reliability of overhead cranes. A total of 47 basic events were identified for ladle fall in overhead cranes. The results showed that the probability of the ladle fall in the FT approach is equal to 0.0523035 and in the BN approach in the prior event is equal to 0.0273394 which is less than the FT method. Based on the values predicted by Markov chain, the reliability of the system decreases over time by $67.9 \%$ after 60 months. This study showed that the plan for ladle fall prevention should consider all influencing parameters identified by proper risk assessment methodologies.
\end{abstract}

\section{Introduction}

There are various techniques and methods to estimate the reliability level of systems. One of the most popular and validated methods for reliability assessment in complex systems is fault tree analysis (FTA). This is based on calculating the occurrence probability of a top event, and in conventional version of this technique, it uses relevant databases containing failure rate data, such as Odisha Renewable Energy Development Agency (OREDA) [1], Center for Chemical Process Safety (CCPS) [2], and Lees [3] to facilitate the estimation of the failure rate of root events.
However, databases have suffered from some limitations such as the lack of failure rates for all root events and the low trustworthiness of the related data. In some resources, such as the NOG-070 report, it has been clearly mentioned that if the number of components subject to failure is less than 30 components, the estimated failure rate will not be sufficiently reliable to assess the system safety [4].

To minimize the uncertainty level, attempts should be made to overcome the inherent limitations of the conventional FTA. One of the important approaches to minimize the level of uncertainty is employing expert's opinions integrated with the fuzzy logic approach to estimate the 
occurrence probability of basic events. This approach has been studied by various researchers, such as Liu et al. [5], Cheliyan and Bhattacharyya [6], Jianxing et al. [7], and Hosseini et al. [8]. The fuzzy method can be a good tool for determining the probability in case of vague and uncertain information [9].

Despite using this approach and reducing the uncertainties raised from divergences in individual opinions, the FTA structure is remaining static and its deductive reasoning became impossible. Haarla et al. used the FTA to analyze the reliability of a power transmission network in relation to system failures. They used FTA and event tree analysis (ETA) integrated with dynamic assessment dynamic simulation of the power system and concluded that their suggested methodology can be employed to estimate the probability of system failure and other states for the system [10]. Rahman et al. used the FTA for customer reliability assessment of a distribution power system which obtained the satisfactory results for estimation frequency of failure and Mean Inactivity Time [11].

In order to overcome the static nature of these techniques, there are several novel and dynamic methods such as Bayesian networks (BNs), fuzzy theory, evidence theory, Monte Carlo models, and Markov model (MM) [12]. Among these methods, BN method is a more appropriate option to reduce uncertainty in risk assessment as well as accident analysis, since it benefited from the dynamic nature. Its appropriate efficiency and performance have been emphasized in various studies including Barua et al. [13], Li et al. [14], and Guo et al. [15]. Today, due to its advantages in high applicability and flexibility, it is becoming a popular method for risk and reliability assessment of systems [16]. There are several studies focusing on reliability assessment using fuzzy FTA and Bayesian networks. For example, Jafari et al. used fuzzy FTA and dynamic BN to estimate the reliability of fire alarm systems. The results of their study showed that the proposed combined method for situations where there is a degree of uncertainty can well predict the reliability of the system [17].

Sýkora et al. used BNs to provide a framework for analyzing the probability of risk. The results of this study showed that BNs provide an effective tool for estimating the probability of events in risk assessment [18]. Shi et al. utilized the Bayesian Regularization Artificial Neural Network method to analyze the risk of offshore platform explosions. They stated that the developed method is appropriate for evaluating an explosion [19]. They provided a method for analyzing urban hydrogen refueling station risk using BNs. They also stated that the developed method would reduce uncertainty and computational costs in fire risk assessment [20].

Li et al. used BN to assess reliability for systems suffering common cause failure. They stated that the proposed method is suitable for assessment in dynamic environments [21]. Markowski et al. [22], Cheliyan and Bhattacharyya [6], and Yazdi et al. [23] combined the fault tree with fuzzy and evidence theories for uncertainty using expert opinion and similar incidents' statistics. Garg confirmed that the proposed method based on fuzzy reliability assessment has satisfactory results to overcome the uncertainty in uncertain environments [24]. Niwas and Garg concluded that the newly introduced methodology using the Markov process effectively analyzes the behavior of a system under the studied conditions [25]. Yazdi et al. took into account the issue of uncertainty in FTA and how it can be reduced in a review article. They emphasized the potency of fuzzy set theory and Bayesian network to overcome the uncertainty level. One of the main recommendations of their study was to pay more attention to the utilization of the integrated approaches especially using the Bayesian network [26].

For repairable and unrepairable systems, other reliability methods can also be used. One of them is the Markov model (MM), which models the random behavior of systems in continuous or discontinuous change states with respect to time or space. This method is based on the assumption that the system has the features of memorization, so that its current behavior is not affected by its past or future records, its current status is important, and its behavior is constant [27]. This means that the system has a constant hazard rate and follows Poisson and exponential distributions. In discrete space and time, space follows the so-called Markov chain and the whole process is called a Markov process [28].

Li et al. developed a method for reliability assessment, and its verification was confirmed using the Monte Carlo technique. They stated that the new model is more effective despite its associated defects [29]. Thimashew and Bushinskaya argued that the Markov process causes the behaviors of a set of seriously developing defects to be considered collectively and as a distribution system [28]. The study of Ossai et al. reported that the Markov process could predict the reliability and the estimation of the residual life of the pipeline systems [30]. Peiravi et al. also showed that new Markov-based model with a significant reduction in computation time is a suitable solution for estimating the system reliability [31].

In integrated approaches, an attempt is made to reduce the limitations of existing methods and obtain more objective results by employing various theories and methods. Therefore, combination of conventional FTA with the novel and suitable theories or methodologies can lead to a more accurate estimate of the probability of basic events and reliability.

Overhead cranes are widely used in the industry for carrying and moving heavy loads. Due to involvement of operators in crane control and operations, there is always a risk of accidents due to human error or equipment failure [5]. In such cases, establishing an adequate level of reliability in the whole system is an important and vital principle, and any fault in paying attention to this can have undesirable consequences. To do this, it is appropriate to have a comprehensive approach for risk and reliability assessment of the most probable failure scenarios during overhead crane operations. As mentioned before, FTA integrated with other approaches seems to meet this objective. Using the present approach can help engineers to reduce the uncertainty levels in risk assessment of overhead cranes. Moreover, they can integrate this approach with other risk assessment methodologies to opt for a more dynamic method. All the 
industries using an overhead crane in their routine lifting operations can consider this approach in their risk management program. Hence, this study aimed to analyze the risks and assess the reliability of overhead cranes using FTA integrated with fuzzy theory and experts' judgment, BN, and MM. The main novelties of the present study are as follows: (1) to our knowledge, this is the first comprehensive study to address dynamic risk analysis and reliability of overhead crane; (2) the integration of FTA with fuzzy approach and BN seems to give better results than traditional FTA; and (3) predicting the reliability of overhead crane system for a fiveyear period can give us proper recommendations for preventive maintenance scheduling.

\section{Materials and Methods}

In this study, FTA in combination with fuzzy theory, Bayesian network, and Markov chain was used to evaluate the reliability of overhead cranes. Figure 1 reveals the schematic diagram of the study methodology. The details of each step are described as follows.

\subsection{Identifying the Structure and Operation of Overhead} Cranes Carrying Ladles. First, detailed information about all components of the system and physical and functional interactions between crane components was gathered. All technical documents related to cranes and procedures of transporting ladles containing molten materials and empty ladles in the steelmaking unit and other documents related to the operations of the cranes were received and reviewed. Relying on the available resources and the experts' opinions in this field led the cranes to be considered in four subsystems, namely, structural, mechanical, electrical, and instrumentation, and safety protection features, so that a comprehensive understanding can be achieved about faults, failures, and defects occurring in the cranes.

\subsection{Identifying Probable Related Scenarios. After recognizing} the structure and operation of overhead cranes carrying ladles and also receiving the experts' opinions, a questionnaire was designed to get the main scenarios for FTA construction. In this regard, five possible scenarios were identified in overhead cranes carrying ladles. Ladle fall was the most important scenario identified based on the experts' opinions, near-miss and accident reports. This scenario was considered to proceed with the present study.

2.3. FTA Development. The FTA method is the most popular and structured technique used to identify the potential causes of an undesirable event or a top event with a safety and economic loss effect [32]. In this method, all the causes of failure are depicted in the form of a tree with an inductive approach or top-down structure; then, constructed structure is analyzed qualitatively or quantitatively to estimate the occurrence probability of the top event [33]. In this study, the FTA was used to identify the basic events affecting the top event and also to estimate its probability of occurrence.
2.4. FTA Validation. Content validity shows the extent to which a tool measures all aspects of a construct. Various indexes are available to estimate the validity of an instrument, among which Content Validity Ratio (CVR) and Content Validity Index (CVI) are considered as the most widely used methods. In this study, these two criteria were employed to examine the relevance and necessity of basic and intermediate events and also to determine the type of gates. To solve the initial uncertainty in the FTA structure, we constructed an expert team including nine experts from the steelmaking plant (such as firefighting manager, HSE experts, electrical and instrumentation experts, repair and maintenance manager, mechanical engineer, and crane supervisor) and two university specialists with risk assessment expertise. The experts' opinions were gathered through the brainstorming method. Figure 2 represents the FTA validation process based on the opinions of the constructed team. Content Validity Ratio (CVR) is a method of measuring the validity of a tool designed by Lawshe [34]. To calculate this ratio, the experts' opinions regarding the test content were used. First, the objectives of the test were explained to the experts, and the operational definitions of the content of the questions were declared. They were then asked to rate each question based on a three-point Likert scale $(1=$ not necessary, 2 = useful but not necessary, and $3=$ necessary). It was then calculated using the following equation:

$$
\mathrm{CVR}=\frac{n_{E}-(N / 2)}{N / 2} .
$$

Here, $n_{E}$ is the number of experts who selected the necessary option and $N$ is the total number of experts.

According to Lawshe's table, the minimum acceptable value of CVR was 0.59 for 11 experts and lower values did not have an acceptable content validity.

The Content Validity Index (CVI) is also used to estimate the validity of the questionnaire provided by Waltz and Bausell [35]. To calculate the CVI, experts were asked to rate the relevance of each item based on a 4-point Likert scale $(1=$ not relevant, $2=$ somewhat relevant, $3=$ quite relevant, and $4=$ very relevant). The number of experts who chose options 3 and 4 was divided by the total number of experts. If the obtained number is less than 0.7 , the item will be rejected. If it is between 0.7 and 0.79 , a review should be performed, and if it is greater than 0.79 , it will be acceptable.

\subsection{Determining the Probability of Basic Events Using Fuzzy} Set Theory (FST). Failure Rate and Event Data (FRED) databases can be used to estimate the probability of occurrence of basic events [36]. However, since in this study no information was available for the identified basic events, the occurrence probability of the initial event was estimated using the experts' opinions and fuzzy theory. This approach can help inspectors in situations where there is ambiguous data and uncertainty of data [37]. In this study, the experts' opinions and inferences and FST were used to determine the probability of basic events. The steps of implementing this theory to determine the probability of basic events are as follows. 


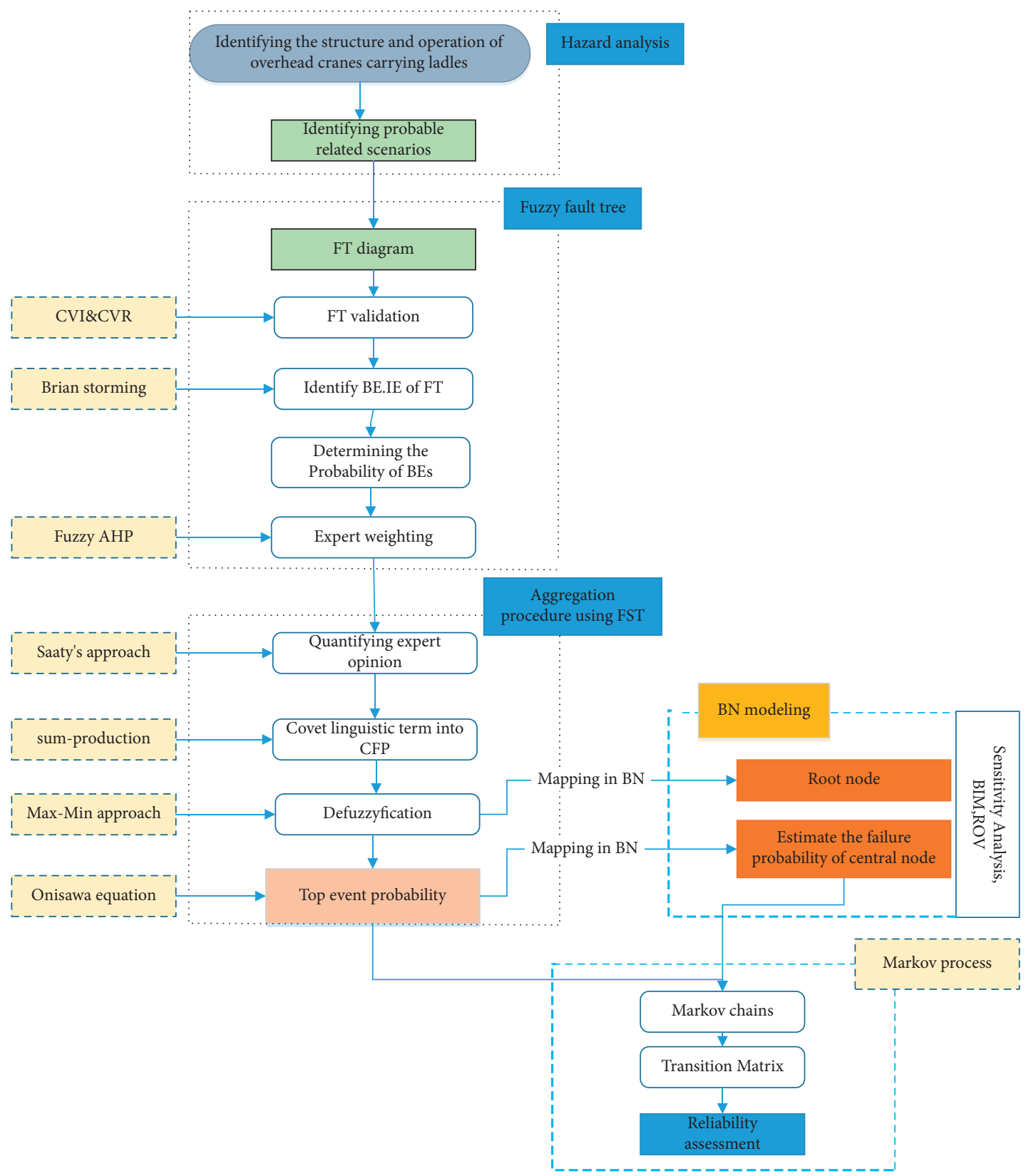

Figure 1: Study methodology.

2.5.1. Weighting the Experts' Opinions Using the Fuzzy Analytic Hierarchy Process (FAHP) Method. Using experienced persons is a way to estimate the probability of events. This method can be employed to provide the solution when we are faced with the challenge of lack of appropriate data [38]. In this study, a heterogeneous group of experts was used. The FAHP method was used to weigh the experts' opinions. The AHP method has been widely used in selecting the best option from among other options using pairwise comparisons for each level according to the objective of selecting the best option, although it has suffered from some limitations. For example, it is primarily used in crisp decisions, examines a very unbalanced scale of judgment, and does not take into account the uncertainties in individual judgments; moreover, the ranking of this method is almost inaccurate. Mental judgments, choices, and performance of decision-makers have a great impact on the AHP results. In addition, the judgment of people about qualitative indicators may be subjective and to some extent imprecise. These limitations can overshadow the efficiency and accuracy of the conventional AHP method when we need to make critical decisions. Fuzzy set theory has the ability to combine with pairwise comparisons to develop the AHP technique in order to overcome the conventional AHP limitations. The combined decision-making technique offers a more accurate understanding of the decision-making process $[39,40]$. In this study, Buckley method according to the study by Yazdi [41] was used to weigh the experts' opinions. 


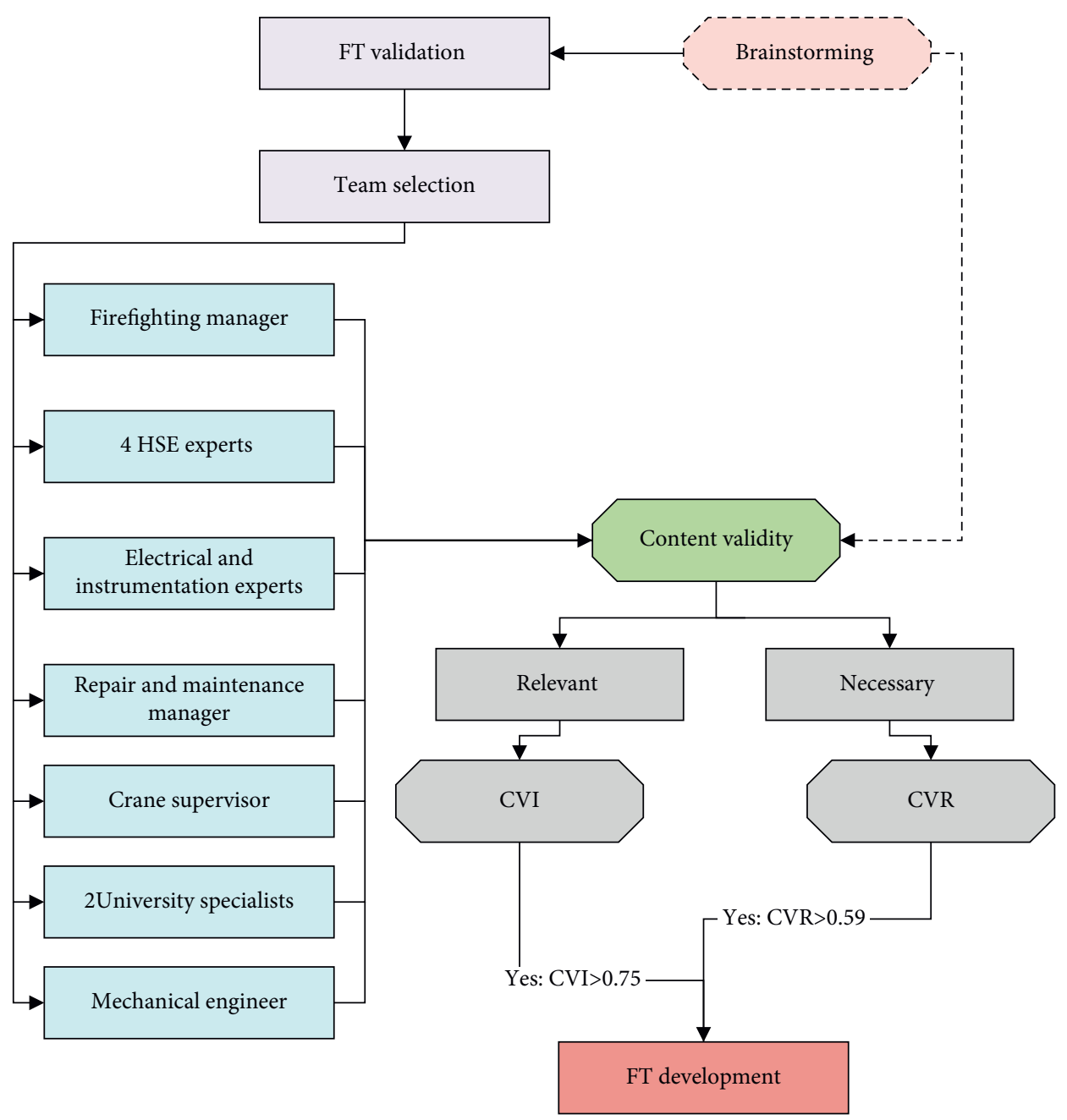

Figure 2: FTA validation process.

2.5.2. Quantifying Experts' Opinions. To quantify the experts' opinions and determine the weight of their opinions on the judgment of failure rate of basic events, the sevenpoint Likert items based on the study of Saaty and Ozdemir [42] were used, namely, very low $(0.2,0.1,0,0)$, low $(0.3,0.2,0.2,0.1)$ relatively low $(0.5,0.4,0.3,0.2)$, medium $(0.6,0.5,0.5,0.4))$, relatively high $(0.8,0.7,0.6$, $0.5)$, high $(0.9,0.8,0.8,0.7)$, and very high $(1,1,0.9,0.8)$. There are several applications of fuzzy set theory to deal with uncertainties and inaccuracy of expert judgment, including triangular, intuitionistic, trapezoidal, and Gaussian fuzzy numbers [43-45]. Trapezoidal and triangular fuzzy numbers describe the fuzzy membership linearly, while the Gaussian function describes fuzzy membership nonlinearly and more flexibly. However, the latter method is more complex than the linear methods, which may cause more inaccuracy [45]. The choice of a certain type of membership function depends on the nature of the problem [46]. In recent studies, the use of triangular and trapezoidal fuzzy numbers has been more effective and more applicable to risk assessment, and studies have used both triangular and trapezoidal fuzzy numbers to transfer linguistic terms to fuzzy membership functions [39, 47, 48]. Therefore, trapezoidal fuzzy numbers were used in this study, and the experts' opinions were quantified using the method proposed by Chen and Hwang [49].

2.5.3. Converting Linguistic Terms into Crisp Failure Possibility (CFP). Experts' judgments in the form of linguistic terms had to be converted to fuzzy numbers and then a final number called fuzzy possibility score (FPS). There are various techniques for consensus of experts, such as linear opinion pool, max-min Delphi method, sum-product, and max-product. In this study, the sum-product algorithm and (2) were used for the consensus of experts [37]:

$$
Z_{i}=\sum_{j=1}^{n} w_{j} f_{i j}, \quad i=1,2, \ldots, m, j=1,2, \ldots, n .
$$

Here, $Z_{i}$ is the failure rate of basic events; $w_{j}$ is the experts' weight $j ; f_{i j}$ are the occurrence probability of fuzzy defect of basic event $i$ stated by the experts $j$; and $n$ and $m$ are the total number of experts and the number of basic events, respectively. 
2.5.4. Defuzzification Process. To make decisions in a fuzzy environment, defuzzifying the fuzzy numbers is very important. The number obtained by experts should be defuzzified. There are several methods for defuzzification, including center of area (CoA) method, max-min, center of the largest area, weighted average, mean max, and bisector $[50,51]$. In this study, $\max -$ min method presented by Shi et al. [52] was used. The max-min fuzzy set method has been used in several studies, including Sharma et al. [53], Shi et al. [52], and Yazdi and Kabir [37]. This method is presented in the following equations: equations:

$$
\begin{gathered}
f_{\text {max }}(x)= \begin{cases}x, & 0 \leq x \leq 1, \\
0, & \text { (otherwise) }\end{cases} \\
f_{\text {max }}(x)= \begin{cases}1-x, & 0 \leq x \leq 1, \\
0, & \text { (otherwise). }\end{cases}
\end{gathered}
$$

In order to calculate the left and right numbers of the fuzzy set, the following equations were used.

$$
\begin{aligned}
& \operatorname{FPS}_{\text {Right }}=\sup _{x}\left[f_{z}(x) \wedge f_{\text {max }}(x)\right]=\frac{(1-d)}{[1+(d-c)]}, \\
& \operatorname{FPS}_{\text {Right }}=\sup _{x}\left[f_{z}(x) \wedge f_{\text {min }}(x)\right]=\frac{(1-a)}{[1+(b-a)]} .
\end{aligned}
$$

Therefore, the probability of the fuzzy number $Z_{i}$ was calculated using the following equation:

$$
\operatorname{FPS}\left(Z_{i}\right)=\frac{\left[\operatorname{FPS}_{\text {Right }}\left(Z_{i}\right)+1-\operatorname{FPS}_{\text {Left }}\left(Z_{i}\right)\right]}{2}
$$

2.5.5. Top Event and Failure Probability. The numbers obtained from the defuzzification step for each event are CFP, and they must be converted from possibility to probability. The following equation was used for this purpose [54]:

$$
\begin{gathered}
\mathrm{FP}=\left\{\begin{aligned}
& 0^{1 / 10^{K}}, \mathrm{CFP} \neq 0, \\
& \mathrm{CFP}=0,
\end{aligned}\right. \\
K=\left[\frac{1-\mathrm{CFP}}{\mathrm{CFP}}\right]^{1 / 3} \times 2.301 .
\end{gathered}
$$

Here, FP is the probability rate of each basic event, CFP is the possibility number obtained from the defuzzification step, and $K$ is an intermediate variable that is a function of CFP.

Finally, the probability of occurrence of intermediate events related to the final event was calculated using the following equations and according to the gate type:

$$
\begin{aligned}
P_{\text {or }} & =1-\prod_{i=1}^{n}(1-P), \\
P_{\text {and }} & =\prod_{i=1}^{n} P_{i},
\end{aligned}
$$

$$
P(\mathrm{TE})=1-\prod_{j=1}^{k}\left(1-P\left(\mathrm{MCS}_{j}\right)\right),
$$

where $P_{i}$ is the probability of the basic event $i, P\left(\mathrm{MCS}_{j}\right)$ is the occurrence probability of the main cut set $j$, and $P(\mathrm{TE})$ is the occurrence probability of TE.

2.6. Bayesian Networks. BN is a graphical model to depict the relationship between the desired variables. This network consists of qualitative and quantitative parts. The qualitative part (structural model) shows the interactions between the variables and a unique continuous probability distribution which is defined on all variables. The quantitative part provides a set of local probability characteristics, which are necessary for inferring probabilities and numerically measuring variables or a set of variables. $\mathrm{BN}$ is a noncircular directional diagram [55], and it not only uses Bayesian theory to update probabilities, but also has a fully flexible and compatible feature for dynamic modeling of a wide range of event scenarios. It uses a set of variables to calculate the joint probability distribution $[56,57]$. In this study, the initial, intermediate, and top events identified by the FTA method were considered as root, intermediate, and top nodes, respectively [58]. One of the most important features of the $\mathrm{BN}$ is the inductive and deductive reasoning ability.

2.6.1. Inductive Reasoning. This type of reasoning is used to predict and estimate the occurrence probability of events and its consequences. Although the FTA model, like BN, is able to make this type of reasoning, due to the mentioned limitations, it may lead to incorrect estimation of the probability of the event scenario and consequently the probability of final consequences $[59,60]$.

2.6.2. Deductive Reasoning. One of the characteristics of $\mathrm{BN}$ is the deductive reasoning ability which is very important in dynamic risk analysis. This advantage makes the network structure dynamic and allows updating the occurrence probability of basic events by providing accident precursors. This makes the model data in the update state closer to reality and creates a dynamic risk analysis model. By updating the occurrence probability of the basic events and the final consequences, it will be possible to select the most critical basic event that has the largest role in the occurrence of the top event [60]. In this study, this type of reasoning was used to update the probability of basic events.

2.7. Sensitivity Analysis in BN. Traditional definitions of significance criteria, such as Ratio of Variation (ROV) and Birnbaum Importance Measure (BIM), are generalized in $\mathrm{BN}$ using probability laws. The new definitions developed in $\mathrm{BN}$ can be used not only to identify critical events, but also to overcome the FTA limitations in this regard [61].

2.7.1. ROV Criterion. In order to compare the probability of prior and posterior basic events and to select the most 
critical basic event, the method of measuring the ROV was used, which was calculated by the following equation [60]:

$$
\operatorname{ROV}\left(\mathrm{BE}_{i}\right)=\frac{\pi\left(\mathrm{BE}_{i}\right)-\theta\left(\mathrm{BE}_{i}\right)}{\theta\left(\mathrm{BE}_{i}\right)} .
$$

Here, $\pi\left(\mathrm{BE}_{i}\right)$ is the posterior probability of the basic event and $\mathrm{BE}_{i} \theta\left(\mathrm{BE}_{i}\right)$ is the prior probability of the basic event $\mathrm{BE}_{i}$.

2.7.2. BIM Criterion. The BIM criterion finds the most important components by how likely it is that the failure or integrity of a component corresponds to the probability of failure or integrity of the system, or in other words to what degree a component is critical to the system. This criterion was calculated using the following equation [48]:

$$
\operatorname{BIM}\left(\mathrm{BE}_{i}\right)=P\left(\mathrm{TE} \mid \mathrm{BE}_{i}=\text { True }\right)-P\left(\mathrm{TE} \mid \mathrm{BE}_{i}=\text { Flse }\right) .
$$

Here, $P\left(\mathrm{TE} \mid \mathrm{BE}_{i}=\right.$ True $)$ is the occurrence probability of TE event when the basic event $\mathrm{BE}_{i}$ in the basic node of the $\mathrm{BN}$ is in True state, and $P\left(\mathrm{TE} \mid \mathrm{BE}_{i}=\right.$ Flse $)$ is the occurrence probability of TE event when the basic event in the basic node of the $\mathrm{BN}$ is in False state.

2.8. Markov Chain. Markov chains are a special state of the Markov process, in which both the t-parameter and the system state select only discrete values. Random variables of $X_{1}, X_{2}, \ldots, X_{n}$ are called Markov chains when (14) is established for all values of $n$ (step) and all states of $i$ and $j$ [27].

$$
P\left[X_{n+1}=j \mid X_{1}=i_{1}, X_{2}=i_{2}, \ldots, X_{n}=i\right]=P\left[X_{n+1}=j \mid X_{n}=i\right] .
$$

2.8.1. Transition Matrix. The transition matrix is called a matrix, the constituent element $(P i j)$ of which is in the row $i$ and column $j$. In other words, $P i j$ indicates the probability of changing the system state from $i$ to $j$. If the system has $M$ states, its transition matrix will be according to the following equation [62]:

$$
P=\left[\begin{array}{cccc}
p_{11} & p_{12} & \cdots & p_{1 M} \\
p_{21} & p_{22} & \cdots & p_{2 M} \\
\cdots & & & \cdots \\
\cdots & & & \cdots \\
p_{M 1} & p_{M 2} & & p_{M M}
\end{array}\right] .
$$

All elements of this matrix are nonnegative, and the sum of the elements in each row is equal to one. In general, any square matrix whose elements are all nonnegative and the sum of its elements in each row is equal to one is called the Markov matrix. The state space diagram is used to make it easier to use Markov processes. All available states for the system and all transition paths from each state are considered, and then the transfer rates of each step are entered.
This diagram is used to further facilitate the analysis of Markov processes.

2.8.2. State Space Diagram. The state space diagram showed the relationship between the states of a Markov system. In this diagram, the nodes represent the state of the system, and the branches represent the possibility of transition from one state to another. The values on the branches indicate the change rate of the system state from $i$ to $j$. For a repairable member, the state space diagram is shown assuming two states of correct function and impaired function, $\lambda$ is the failure rate or state change from the correct to impaired function, and $\mu$ is the repair rate of the failed member to achieve correct function [62]. In this study, the state space diagram was used for a single member. Figure 3 shows the state space diagram for the overhead crane carrying a melting ladle.

\section{Results}

After analyzing the overhead crane system and receiving the experts' opinions the questionnaire was designed to identify the main scenarios of the FT. Finally, according to the results of the questionnaires and the experts' opinions, 5 important scenarios were identified, namely, pouring and splashing of molten material, ladle fall, objects fall, falling of people from height due to working on cranes or related equipment, and falling of other objects carried by the crane. Figure 4 shows the relative frequency of each scenario according to the results of the questionnaires. As demonstrated, ladle fall has the highest relative frequency which was selected as the most probable scenario.

3.1. Drawing and Validating the FT. The FT related to the ladle fall from the overhead crane was constructed by the panel of experts and operatives (Figure 5). After drawing the FT, the content validity of the basic events in terms of the type of gate and their location was evaluated by the panel of experts using the CVI and CVR. In this study, X14 (human error in case of reeving ropes) was considered as a common event between IE19 and IE21 events. The gate between basic events for the IE22 intermediate event was considered "or." The CVI for the final basic events was greater than 0.79 , and the CVR value for the final basic events was greater than 0.59 . As a result, 29 basic events and 13 final events were identified.

According to Figure 5, the main causes for the ladle fall were identified and are demonstrated in Figures 6-8. Tables 1 and 2 represent the list of intermediate events due to crane-related failures and basic events, respectively. The results of qualitative evaluation of the fault tree showed that a total of 27 intermediate events and 47 root events were identified in the melting ladle scenario.

3.2. Determining the Probability of Basic Events Using Fuzzy Logic. In order to determine the probability of the top event, it is necessary to calculate the probability of the basic events. 


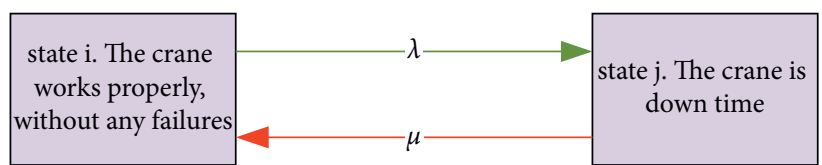

FIgURE 3: State space diagram for the overhead crane carrying a melting ladle.

falling of other objects carried by the crane

falling of people from height due to working on cranes or related equipment

웛ำ

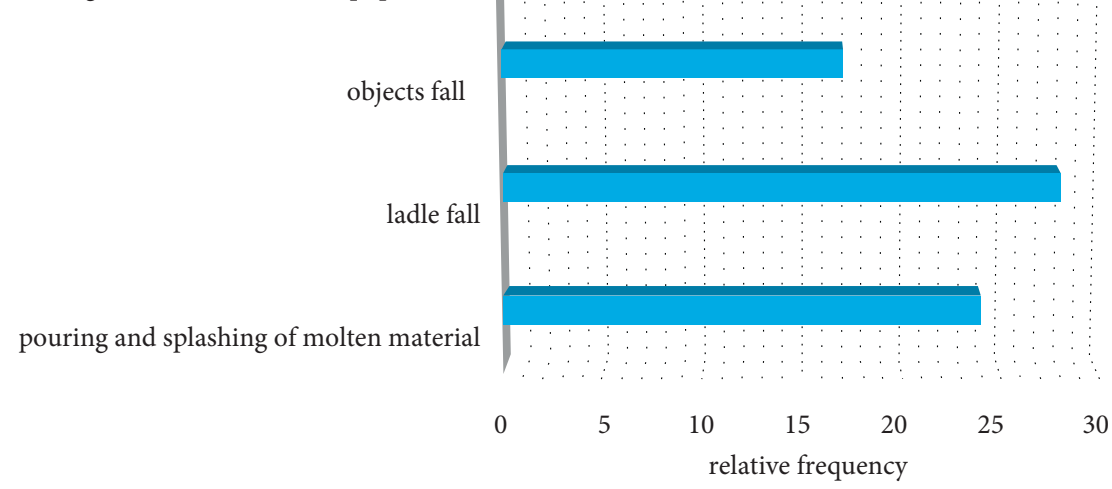

FIgURE 4: Relative frequency of the identified scenarios.

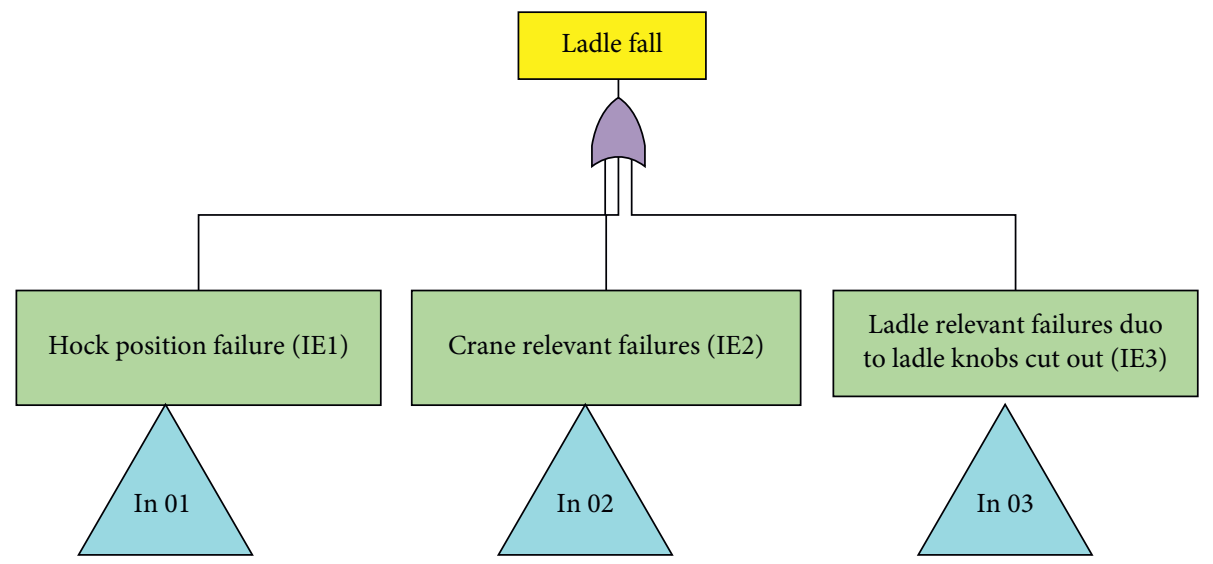

FIGURE 5: FT diagram of the ladle fall from the overhead crane.

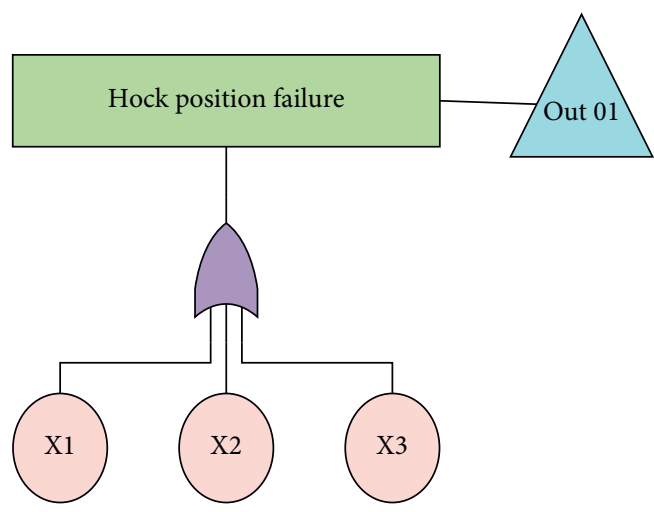

Figure 6: Hock position failure. 


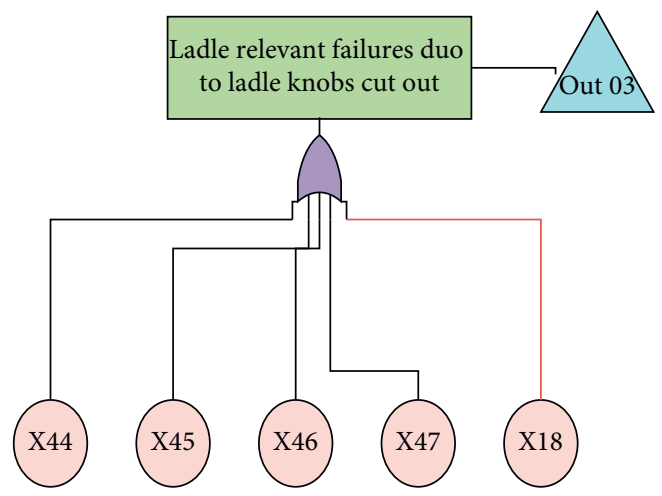

FIGURE 7: Ladle-related failures due to ladle knobs cutting out.

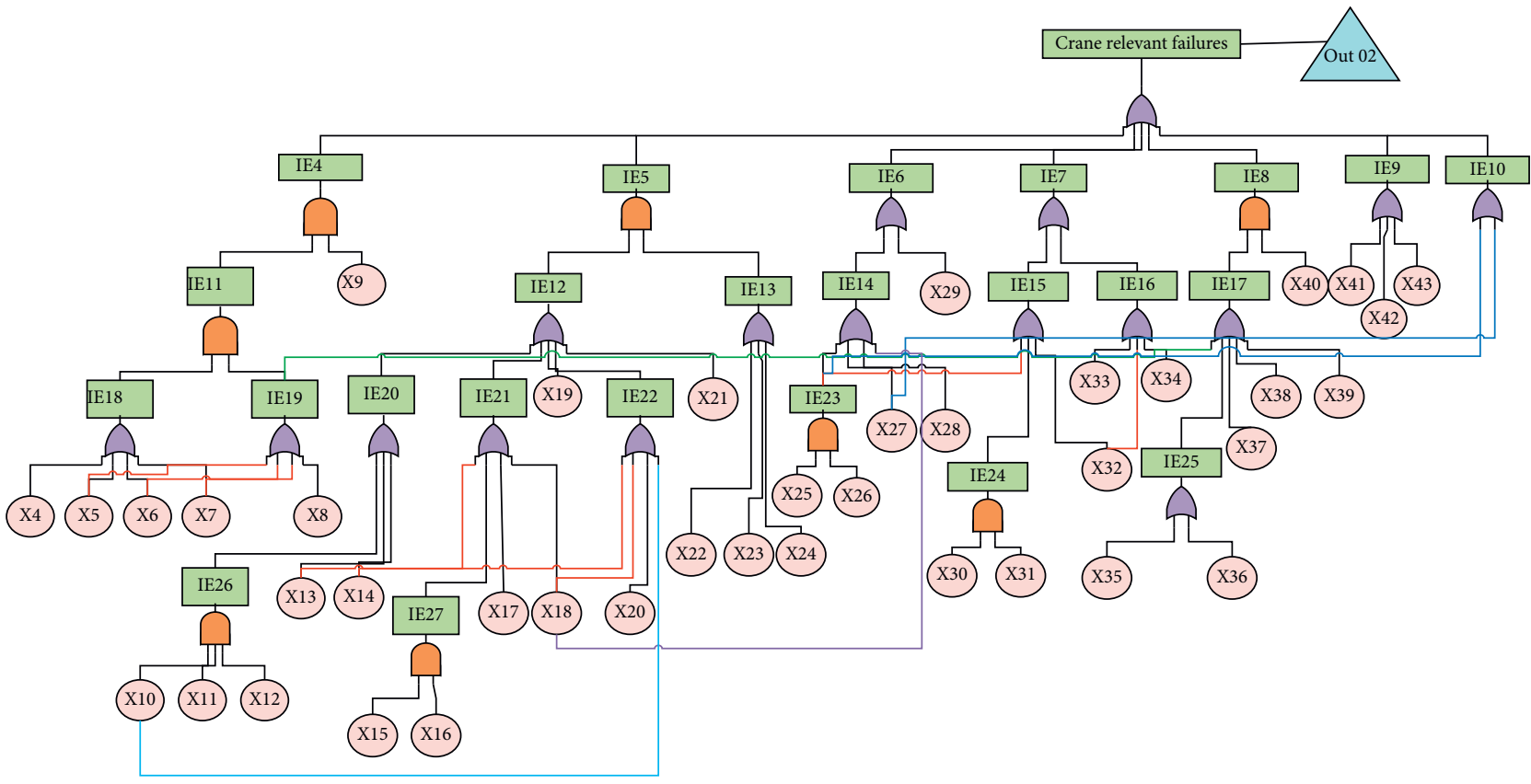

FIgURE 8: Crane-related failures.

A 7-term linguistic scale was used to determine the occurrence probability of basic events. According to Ishikawa et al. [63], the three experts selected to determine the probability of the basic events in this study were fully aware of the system. Yazdi and Zarei [44] and Omidvari et al. [64] also used three experts to determine the probability of basic events based on the experts' opinion. The experts in this study were overhead crane repair expert, overhead crane electrical expert, and PM overhead crane expert. The FAHP method was used to calculate the weight. The experts' information system is shown in Figure 9, and Table 3 shows the experts' weighting profile. Table 3 reveals that expert No. 1 (overhead crane repair expert) had the highest weight and expert No. 3 (overhead crane electrical expert) had the lowest weight.

In the next step, fuzzy numbers equivalent to the theories of each expert were estimated separately. These fuzzy numbers were then defuzzified, and finally the occurrence probability of each basic event was calculated; the results are presented in Table 4. As seen in the table, the lowest probability was related to the X30 basic event (lack of spare parts), the probability of which was estimated to be 0.0007656 , and 16 basic events had the highest probability which was 0.0020797 per year.

After determining the probability of basic events, the probability of the top event was calculated to be 0.052303 in the FT method according to the type of gate.

\subsection{Determining the Probability of Basic Events Using Fuzzy $B N$}

3.3.1. Ladle Fall. After determining the probability of basic events using fuzzy logic, the obtained results were entered into GeNIe software according to the method presented in this study, and the prior and posterior probabilities were determined by updating BN. Figure 10 shows an overview of $\mathrm{BN}$ modeling. 
TABle 1: Describing intermediate events due to crane-related failures.

\begin{tabular}{lc}
\hline Symbol & Intermediate event \\
\hline IE4 & Hoisting stop failure \\
IE5 & Wire rope running out \\
IE6 & Lifting beam rupture \\
IE7 & Hock failure \\
IE8 & Hoisting emergency brake failure \\
IE9 & Critical joint connection failure \\
IE10 & Structure failure in case of main girder \\
IE11 & Brake failure \\
IE12 & Wire rope tearing \\
IE13 & Rope faster running out \\
IE14 & Main body fracture \\
IE15 & Lamellar hock body breakdown \\
IE16 & Hock running out \\
IE17 & Overspeed \\
IE18 & EMG brake failure \\
IE19 & General brake failure \\
IE20 & Excessive tension \\
IE21 & Excessive twisting \\
IE22 & Rope contact \\
IE23 & Overload \\
IE24 & Hock damage \\
IE25 & Power transmission \\
IE26 & Impact during lifting \\
IE27 & Wire rope deformation \\
\hline
\end{tabular}

According to Table 5, 47 basic events were identified for ladle fall in overhead cranes. The FT results showed that the lowest probability was that of BE30 (lack of spare parts) and BE19 (poor lubrication).

3.3.2. Deductive and Inductive Reasoning. Inductive reasoning is the common features of both FT and BN. Columns 2, 6,3 , and 7 of Table 5 show the results of inductive reasoning. The results showed that the probability of the top event is equal to 0.0523035 and in the $\mathrm{BN}$ approach in the prior event is equal to 0.0273394 which is less than that of the FT method.

One of the special features of the BN method is deductive reasoning; that is, it is possible to update the basic events by receiving accident and near-miss data, converting the $\mathrm{BN}$ model to dynamic model.

Columns 4 and 8 of Table 5 show the results of deductive reasoning or updated probabilities of basic events calculated using GeNIe software for basic events. The results of updating the basic events in the $\mathrm{BN}$ allow us to choose the most important basic event. Updated values of probability of basic events indicated that BE46 (fatigue due to overheating of molten metal), BE27 (body crack), and BE41 (longitudinal weld of girder failure) had the highest role in the occurrence of the top event. However, BE30 (lack of spare parts), BE35 (Cardan shaft breakage), and BE36 (Cardan coupling breakage) had the lowest role in the occurrence of top events.

3.3.3. Sensitivity Analysis. In this study, BIM and ROV methods were used to analyze the sensitivity of $\mathrm{BN}$ as well as identify the most critical basic event. Figure 11 shows the
TABLE 2: Describing basic events.

\begin{tabular}{|c|c|}
\hline Symbol & Basic event \\
\hline $\mathrm{X} 1$ & $\begin{array}{l}\text { Human error in case of unsuitable hook fitness before } \\
\text { lifting }\end{array}$ \\
\hline $\mathrm{X} 2$ & Hook span defect \\
\hline $\mathrm{X} 3$ & Hook misalignment ESP due to pin jamming \\
\hline $\mathrm{X} 4$ & Worn gasket \\
\hline $\mathrm{X} 5$ & Break maladjustment \\
\hline $\mathrm{X} 6$ & Break disk damage \\
\hline $\mathrm{X} 7$ & Mechanical parts failure \\
\hline $\mathrm{X} 8$ & Worn shoes \\
\hline X9 & Suspended load at height \\
\hline $\mathrm{X} 10$ & Human error in case of operation \\
\hline $\mathrm{X} 11$ & Upper limit switch failure \\
\hline $\mathrm{X} 12$ & Absolute encoder failure \\
\hline $\mathrm{X} 13$ & Improper wire rope selection \\
\hline $\mathrm{X} 14$ & Human error in case of reeving ropes \\
\hline $\mathrm{X} 15$ & Human error in case of hook positioning \\
\hline $\mathrm{X} 16$ & Lower stop limit switch failure \\
\hline $\mathrm{X} 17$ & Wipe rope overlapping due to lack of rope guard \\
\hline $\mathrm{X} 18$ & Third party damage \\
\hline $\mathrm{X} 19$ & Poor lubrication \\
\hline $\mathrm{X} 20$ & Lack of rope guard \\
\hline $\mathrm{X} 21$ & Overheating due to molten metal splash \\
\hline $\mathrm{X} 22$ & Shaft rupture \\
\hline $\mathrm{X} 23$ & Socket failure \\
\hline $\mathrm{X} 24$ & Cotter pins failure \\
\hline $\mathrm{X} 25$ & Load detection system failure \\
\hline $\mathrm{X} 26$ & Human error in case of overloading \\
\hline $\mathrm{X} 27$ & Body crack \\
\hline $\mathrm{X} 28$ & Overheating \\
\hline $\mathrm{X} 29$ & Joint connection failure in case of lifting beam rupture \\
\hline $\mathrm{X} 30$ & Lack of spare parts \\
\hline $\mathrm{X} 31$ & Poor inspection test \\
\hline $\mathrm{X} 32$ & Lamellar hook pin failure \\
\hline $\mathrm{X} 33$ & Joint connection failure in case of hook running out \\
\hline $\mathrm{X} 34$ & Cross joint pin failure \\
\hline $\mathrm{X} 35$ & Cardan shaft breakage \\
\hline $\mathrm{X} 36$ & Cardan coupling breakage \\
\hline $\mathrm{X} 37$ & Shaft encoder \\
\hline $\mathrm{X} 38$ & Inverter control unit failure \\
\hline $\mathrm{X} 39$ & Joy stick failure \\
\hline $\mathrm{X} 40$ & Overspeed device failure \\
\hline $\mathrm{X} 41$ & Longitudinal weld of girder failure \\
\hline $\mathrm{X} 42$ & Groove welds failure \\
\hline $\mathrm{X} 43$ & High tension bolts failure \\
\hline $\mathrm{X} 44$ & Knob joint connections failure within welding points \\
\hline $\mathrm{X} 45$ & Knob ridge fraction due to welding points defect \\
\hline $\mathrm{X} 46$ & Fatigue due to overheating of molten metal \\
\hline X47 & $\begin{array}{c}\text { Knob corrosion due to molten metal permeation to } \\
\text { refractory }\end{array}$ \\
\hline
\end{tabular}

results of sensitivity analysis by ROV method. As seen, 17 basic events had the highest amount of ROV, among which BE46 and BE1 events were identified as the most important basic events.

Figure 12 demonstrates the results of sensitivity analysis using the BIM criterion. As depicted, 18 basic events had the highest probability, among which BE46, $\mathrm{BE} 32, \mathrm{BE} 33$, and BE27 were identified as the most important basic events influencing the occurrence of the top event. 


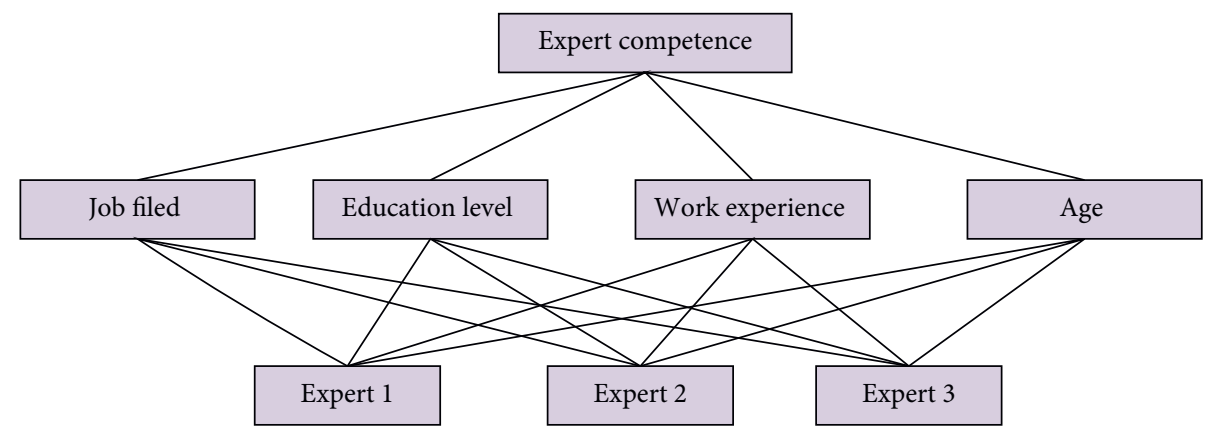

FIGURE 9: FAHP indicator system for qualification assessment of the experts.

TABLE 3: Experts' weighting profile.

\begin{tabular}{|c|c|c|c|c|c|}
\hline Expert code & Job filed & Education level & Work experience & Age & Weighted score \\
\hline Expert 1 & Repair expert & MSc & $2-10$ & $40-49$ & 0.413 \\
\hline Expert 2 & Overhead crane expert & BSc & $2-10$ & $30-39$ & 0.343 \\
\hline Expert 3 & Electrical expert of overhead cranes & BSc & $2-10$ & $30-39$ & 0.271 \\
\hline
\end{tabular}

After determining the main root events, the effectiveness of reducing the probability was evaluated by assuming that each of the root events was zero. The results of sensitivity analysis showed that the most important basic events are BE46, BE32, BE33BE34, and BE27. Events BE32, BE33, and $\mathrm{BE} 34$ were of equal importance, and to assess effectiveness only one of them was considered. Table 6 reveals the results of estimating the probability of the top event occurring in the current situation and assuming that some important events are zero.

3.4. Reliability Estimation. In this study, in order to predict the reliability with the experts' opinions, a 5-year period of time was selected. The initial probability of the ladle fall was estimated by BN and FT methods, which is $0.0273394 \mathrm{yr}^{-1}$ $\left(3.13 E-6 \mathrm{hr}^{-1}\right)$. The repair rate was $0.175\left(\mathrm{hr}^{-1}\right)$ as provided by the maintenance unit of the industry. Figure 13 shows the modeling results of overhead cranes based on FT and BN results over a 5-year period. It indicates that, according to the current situation in the studied system, if no plan is taken to reduce the probability of basic events, the reliability of the system will decrease from $97.3 \%$ to $31.3 \%$ after 5 years.

\section{Discussion}

In developing countries, since there is no database for the failure rate of basic events, it is not possible to calculate the probability; therefore, fuzzy logic can be used to reduce the uncertainties in the lack of proper data [65]. Estimating the occurrence probability of events is possible through two ways. The first way is the use of classical methods derived from definite mathematics, requiring accurate and quantitative data. This limitation leads to inflexibility and reduced accuracy in mathematical models. The second means is to employ accident databases, which may have more controversial validity than real data of events. Regarding the point that the main assumption in classical method is the uncertainty about the feature, the parameters are determined definitively, and conventional models do not provide an accurate estimation about reality. However, fuzzy logic can examine parameters in an interval [66].

In this study, fuzzy logic and a heterogeneous group of experts were used to determine the probability of basic events. This method can improve the reliability and reduce system costs by reducing uncertainty and ambiguity. The method used in the study of Jafari et al. [67] is consistent with the method used in the present study. In this study, Winkler and Clemen methods were used to weigh the experts' opinions, and the max-min method was used for defuzzification. The difference between this study and the study by Jafari et al. is the use of max-min method in defuzzifying the probability of basic events. Yazdi et al. used the sum-product method for consensus of experts and the max-min method for defuzzification. According to Yazdi and Kabir, the max-min method is a popular method for defuzzifying linguistic terms [37]. The mentioned methods are consistent with the method used in the present study. Yazdi and Zarei compared the sum-production/CoA method with the sum-production/max-min method in fuzzy theory to estimate the probability of basic events and the top event. They found that the sum-production/CoA method is a reliable and suitable method for complex systems in safety assessment. In this study, sum-production/max-min method was used to estimate the probability of basic events and the top event (ladle fall). In order to validate the FT, a team consisting of relevant and university experts was formed. Given the wide range of researchers in various industries and their unfamiliarity with all aspects of systems, the university-industry interaction can make it possible to exchange information, which has had positive effects on large companies [44]. In this study, CVI and CVR were used for initial validation of the FT structure. The relationship and necessity of the existence of basic events as well as the type of 
TABle 4: Experts' opinions and fuzzy probability of basic events.

\begin{tabular}{|c|c|c|c|c|c|c|c|c|c|c|}
\hline $\mathrm{BE}$ & & $E 2$ & & & y corre & ing nus & & $d$ & $K$ & FP \\
\hline 1 & $\mathrm{FH}$ & $\mathrm{H}$ & $\mathrm{M}$ & 0.568 & 0.67 & 0.746 & 0.849 & 0.328 & 2.922 & 0.00119647 \\
\hline 2 & $\mathrm{H}$ & $\mathrm{H}$ & $\mathrm{FH}$ & 0.716 & 0.822 & 0.822 & 0.924 & 0.378 & 2.717 & 0.00191867 \\
\hline 3 & $\mathrm{M}$ & $\mathrm{H}$ & $\mathrm{M}$ & 0.526 & 0.629 & 0.663 & 0.766 & 0.342 & 2.862 & 0.00137404 \\
\hline 4 & $\mathrm{M}$ & FL & $\mathrm{L}$ & 0.637 & 0.74 & 0.843 & 0.904 & 0.343 & 2.858 & 0.00138676 \\
\hline 5 & $\mathrm{VH}$ & $\mathrm{H}$ & $\mathrm{M}$ & 0.822 & 0.924 & 1.027 & 1.027 & 0.387 & 2.682 & 0.0020797 \\
\hline 6 & $\mathrm{VH}$ & $\mathrm{H}$ & VH & 0.822 & 0.924 & 1.027 & 1.027 & 0.387 & 2.682 & 0.0020797 \\
\hline 7 & $\mathrm{VH}$ & $\mathrm{H}$ & $\mathrm{FH}$ & 0.822 & 0.924 & 1.027 & 1.027 & 0.387 & 2.682 & 0.0020797 \\
\hline 8 & $\mathrm{VH}$ & $\mathrm{FH}$ & $\mathrm{H}$ & 0.794 & 0.897 & 0.973 & 1 & 0.385 & 2.69 & 0.00204174 \\
\hline 9 & $\mathrm{H}$ & $\mathrm{H}$ & $\mathrm{H}$ & 0.78 & 0.833 & 0.944 & 0.986 & 0.384 & 2.694 & 0.00202302 \\
\hline 10 & VH & $\mathrm{VH}$ & $\mathrm{VH}$ & 0.822 & 0.924 & 1.027 & 1.027 & 0.387 & 2.682 & 0.0020797 \\
\hline 11 & $\mathrm{VH}$ & $\mathrm{FH}$ & $\mathrm{FH}$ & 0.822 & 0.924 & 1.027 & 1.027 & 0.387 & 2.682 & 0.0020797 \\
\hline 12 & $\mathrm{VH}$ & $\mathrm{H}$ & $\mathrm{H}$ & 0.822 & 0.924 & 1.027 & 1.027 & 0.387 & 2.682 & 0.0020797 \\
\hline 13 & $\mathrm{VH}$ & $\mathrm{FH}$ & $\mathrm{VH}$ & 0.822 & 0.924 & 1.027 & 1.027 & 0.387 & 2.682 & 0.0020797 \\
\hline 14 & $\mathrm{VH}$ & $\mathrm{VH}$ & VH & 0.822 & 0.924 & 1.027 & 1.027 & 0.387 & 2.682 & 0.0020797 \\
\hline 15 & $\mathrm{VH}$ & $\mathrm{VH}$ & $\mathrm{VH}$ & 0.794 & 0.897 & 0.973 & 1 & 0.385 & 2.69 & 0.00204174 \\
\hline 16 & $\mathrm{VH}$ & $\mathrm{FH}$ & $\mathrm{VH}$ & 0.822 & 0.924 & 1.027 & 1.027 & 0.387 & 2.682 & 0.0020797 \\
\hline 17 & $\mathrm{FH}$ & $\mathrm{M}$ & $\mathrm{M}$ & 0.636 & 0.739 & 0.78 & 0.883 & 0.35 & 2.828 & 0.00148594 \\
\hline 18 & M & M & M & 0.541 & 0.644 & 0.671 & 0.773 & 0.347 & 2.841 & 0.00144212 \\
\hline 19 & $\mathrm{M}$ & $\mathrm{L}$ & $\mathrm{L}$ & 0.472 & 0.575 & 0.636 & 0.739 & 0.324 & 2.94 & 0.00114815 \\
\hline 20 & $\mathrm{FH}$ & FL & $\mathrm{L}$ & 0.582 & 0.685 & 0.753 & 0.856 & 0.332 & 2.905 & 0.00124451 \\
\hline 21 & $\mathrm{M}$ & FL & $\mathrm{L}$ & 0.541 & 0.644 & 0.671 & 0.773 & 0.347 & 2.841 & 0.00144212 \\
\hline 22 & $\mathrm{VH}$ & $\mathrm{FH}$ & $\mathrm{H}$ & 0.637 & 0.74 & 0.843 & 0.904 & 0.343 & 2.858 & 0.00138676 \\
\hline 23 & VH & $\mathrm{FH}$ & $\mathrm{H}$ & 0.787 & 0.89 & 0.958 & 0.993 & 0.385 & 2.69 & 0.00204174 \\
\hline 24 & $\mathrm{M}$ & $\mathrm{FH}$ & M & 0.622 & 0.725 & 0.752 & 0.828 & 0.369 & 2.752 & 0.00177011 \\
\hline 25 & $\mathrm{H}$ & $\mathrm{VH}$ & $\mathrm{H}$ & 0.466 & 0.569 & 0.603 & 0.706 & 0.336 & 2.888 & 0.0012942 \\
\hline 26 & $\mathrm{VH}$ & $\mathrm{VH}$ & $\mathrm{H}$ & 0.794 & 0.897 & 0.973 & 1 & 0.385 & 2.69 & 0.00204174 \\
\hline 27 & $\mathrm{VH}$ & $\mathrm{VH}$ & $\mathrm{H}$ & 0.794 & 0.897 & 0.973 & 1 & 0.385 & 2.69 & 0.00204174 \\
\hline 28 & $\mathrm{M}$ & $\mathrm{H}$ & $\mathrm{H}$ & 0.519 & 0.622 & 0.649 & 0.725 & 0.36 & 2.787 & 0.00163305 \\
\hline 29 & $\mathrm{H}$ & $\mathrm{FH}$ & $\mathrm{H}$ & 0.65 & 0.753 & 0.787 & 0.89 & 0.355 & 2.808 & 0.00155597 \\
\hline 30 & FL & $\mathrm{L}$ & $\mathrm{L}$ & 0.178 & 0.281 & 0.357 & 0.459 & 0.287 & 3.116 & 0.0007656 \\
\hline 31 & $\mathrm{VH}$ & $\mathrm{VH}$ & $\mathrm{VH}$ & 0.822 & 0.924 & 1.027 & 1.027 & 0.387 & 2.682 & 0.0020797 \\
\hline 32 & $\mathrm{VH}$ & $\mathrm{FH}$ & $\mathrm{VH}$ & 0.822 & 0.924 & 1.027 & 1.027 & 0.387 & 2.682 & 0.0020797 \\
\hline 33 & $\mathrm{VH}$ & $\mathrm{FH}$ & $\mathrm{H}$ & 0.822 & 0.924 & 1.027 & 1.027 & 0.387 & 2.682 & 0.0020797 \\
\hline 34 & $\mathrm{VH}$ & $\mathrm{H}$ & $\mathrm{VH}$ & 0.822 & 0.924 & 1.027 & 1.027 & 0.387 & 2.682 & 0.0020797 \\
\hline 35 & $\mathrm{FH}$ & $\mathrm{M}$ & $\mathrm{FH}$ & 0.582 & 0.685 & 0.753 & 0.856 & 0.332 & 2.905 & 0.00124451 \\
\hline 36 & $\mathrm{FH}$ & $\mathrm{H}$ & $\mathrm{FH}$ & 0.582 & 0.685 & 0.753 & 0.856 & 0.332 & 2.905 & 0.00124451 \\
\hline 37 & $\mathrm{VH}$ & $\mathrm{FH}$ & $\mathrm{FH}$ & 0.822 & 0.924 & 1.027 & 1.027 & 0.387 & 2.682 & 0.0020797 \\
\hline 38 & $\mathrm{M}$ & $\mathrm{M}$ & $\mathrm{M}$ & 0.411 & 0.513 & 0.513 & 0.616 & 0.346 & 2.845 & 0.00142889 \\
\hline 39 & $\mathrm{FH}$ & $\mathrm{FH}$ & $\mathrm{FH}$ & 0.568 & 0.67 & 0.746 & 0.849 & 0.328 & 2.922 & 0.00119674 \\
\hline 40 & $\mathrm{VH}$ & $\mathrm{H}$ & $\mathrm{H}$ & 0.822 & 0.924 & 1.027 & 1.027 & 0.387 & 2.682 & 0.0020797 \\
\hline 41 & $\mathrm{H}$ & $\mathrm{H}$ & $\mathrm{FH}$ & 0.764 & 0.849 & 0.876 & 0.951 & 0.381 & 2.705 & 0.00197242 \\
\hline 42 & $\mathrm{FH}$ & $\mathrm{FH}$ & $\mathrm{M}$ & 0.582 & 0.685 & 0.753 & 0.856 & 0.332 & 2.905 & 0.00124451 \\
\hline 43 & $\mathrm{FH}$ & $\mathrm{H}$ & $\mathrm{M}$ & 0.582 & 0.685 & 0.753 & 0.856 & 0.332 & 2.905 & 0.00124451 \\
\hline 44 & $\mathrm{FH}$ & $\mathrm{H}$ & $\mathrm{FH}$ & 0.568 & 0.67 & 0.746 & 0.849 & 0.328 & 2.922 & 0.00119674 \\
\hline 45 & $\mathrm{FH}$ & $\mathrm{H}$ & $\mathrm{FH}$ & 0.568 & 0.67 & 0.746 & 0.849 & 0.328 & 2.922 & 0.00119674 \\
\hline 46 & $\mathrm{VH}$ & $\mathrm{H}$ & $\mathrm{FH}$ & 0.822 & 0.924 & 1.027 & 1.027 & 0.387 & 2.682 & 0.0020797 \\
\hline 47 & $\mathrm{FH}$ & $\mathrm{H}$ & $\mathrm{FL}$ & 0.582 & 0.685 & 0.753 & 0.856 & 0.332 & 2.905 & 0.00124451 \\
\hline
\end{tabular}

gates between the basic events and their location were investigated by a team of steel industry experts using these criteria.

According to Figures 5-8, the results of the qualitative constructing of the FT, a total of 74 causes or failure ( 47 basic events and 27 intermediate events) were involved in the ladle fall. The probability of the ladle fall from the overhead crane was estimated to be 0.0523035 , and in the $\mathrm{BN}$ method this value was 0.0273394 using the fuzzy FT. The estimated value in $\mathrm{BN}$ is less than the value of the FT approach. The difference in values obtained by these two methods is due to considering the conditional dependence between the root and intermediate events as a common cause. The FT method is not able to consider these dependencies. Therefore, it can be concluded that some events are statistically interdependent using the BN model. For example, event X10 (human error in case of operation) is a common basic event between IE20 and IE 22. Event X18 (EMG brake failure) is also a common basic event between IE21, IE22, IE23, and IE14 basic events. The effect of these dependencies can be observed in estimating the probability of the top event, i.e., the probability of the ladle falling from the overhead crane. Identifying the critical events that play a major role in the occurrence of the top event is one of the important issues for 


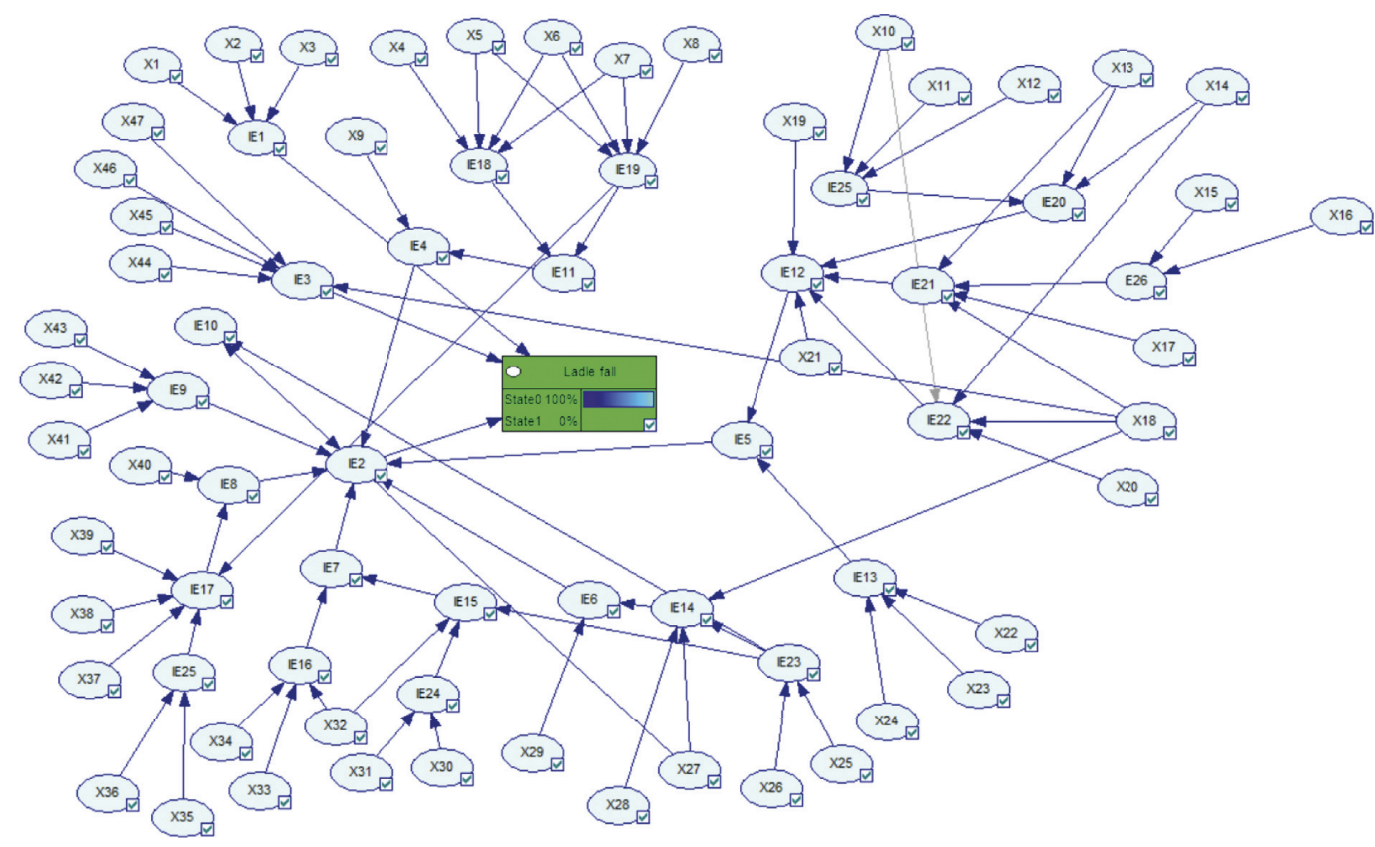

Figure 10: BN structure based on the FT.

TABle 5: Determining the probability of basic and final events using the FT and BN approaches.

\begin{tabular}{|c|c|c|c|c|c|c|c|}
\hline $\mathrm{BE}$ & $\begin{array}{l}\text { Prior probability } \\
\text { (FT) }\end{array}$ & $\begin{array}{c}\text { Prior probability } \\
\text { (BN) }\end{array}$ & $\begin{array}{c}\text { Posterior probability } \\
(\mathrm{BN})\end{array}$ & $\mathrm{BE}$ & $\begin{array}{l}\text { Prior probability } \\
\text { (FT) }\end{array}$ & $\begin{array}{c}\text { Prior probability } \\
\text { (BN) }\end{array}$ & $\begin{array}{l}\text { Posterior probability } \\
\text { (BN) }\end{array}$ \\
\hline 1 & 0.00119647 & 0.00119647 & 0.04377341 & 25 & 0.0012942 & 0.0012942 & 0.00138808 \\
\hline 2 & 0.00191867 & 0.00191867 & 0.07017959 & 26 & 0.00204174 & 0.00204174 & 0.00213555 \\
\hline 3 & 0.00137404 & 0.00137404 & 0.05025855 & 27 & 0.00204174 & 0.00204174 & 0.07468115 \\
\hline 4 & 0.00138676 & 0.00138676 & 0.00138696 & 28 & 0.00163305 & 0.00163305 & 0.05973241 \\
\hline 5 & 0.0020797 & 0.0020797 & 0.00237966 & 29 & 0.00155597 & 0.00155597 & 0.05691304 \\
\hline 6 & 0.0020797 & 0.0020797 & 0.00237966 & 30 & 0.0007656 & 0.0007656 & 0.00082220 \\
\hline 7 & 0.0020797 & 0.0020797 & 0.00237966 & 31 & 0.0020797 & 0.0020797 & 0.00213622 \\
\hline 8 & 0.00204174 & 0.00204174 & 0.00219069 & 32 & 0.0020797 & 0.0020797 & 0.07606962 \\
\hline 9 & 0.00202302 & 0.00202302 & 0.00246952 & 33 & 0.0020797 & 0.0020797 & 0.07606962 \\
\hline 10 & 0.0020797 & 0.0020797 & 0.00250701 & 34 & 0.0020797 & 0.0020797 & 0.07606962 \\
\hline 11 & 0.0020797 & 0.0020797 & 0.0020797 & 35 & 0.00124451 & 0.00124451 & 0.00133518 \\
\hline 12 & 0.0020797 & 0.0020797 & 0.0020797 & 36 & 0.00124451 & 0.00124451 & 0.00133518 \\
\hline 13 & 0.0020797 & 0.0020797 & 0.00250701 & 37 & 0.0020797 & 0.0020797 & 0.00223121 \\
\hline 14 & 0.0020797 & 0.0020797 & 0.00250701 & 38 & 0.00142889 & 0.00142889 & 0.00153299 \\
\hline 15 & 0.00204174 & 0.00204174 & 0.00204261 & 39 & 0.00119674 & 0.00119674 & 0.00128392 \\
\hline 16 & 0.0020797 & 0.0020797 & 0.00208057 & 40 & 0.0020797 & 0.0020797 & 0.00321367 \\
\hline 17 & 0.00148594 & 0.00148594 & 0.00179125 & 41 & 0.00197242 & 0.00197242 & 0.07214562 \\
\hline 18 & 0.00144212 & 0.00144212 & 0.05274872 & 42 & 0.00124451 & 0.00124451 & 0.04552070 \\
\hline 19 & 0.00114815 & 0.00114815 & 0.00138406 & 43 & 0.00124451 & 0.00124451 & 0.04552070 \\
\hline 20 & 0.00124451 & 0.00124451 & 0.00150022 & 44 & 0.00119674 & 0.00119674 & 0.04377341 \\
\hline 21 & 0.00144212 & 0.00144212 & 0.00173843 & 45 & 0.00119674 & 0.00119674 & 0.04377341 \\
\hline 22 & 0.00138676 & 0.00138676 & 0.00287280 & 46 & 0.0020797 & 0.0020797 & 0.07609662 \\
\hline 23 & 0.00204174 & 0.00204174 & 0.00287280 & 47 & 0.00124451 & 0.00124451 & 0.04552033 \\
\hline 24 & 0.00177011 & 0.00177011 & 0.00249061 & $\mathrm{TE}$ & 0.0523035 & 0.0273394 & 1 \\
\hline
\end{tabular}

providing preventive measures. The $\mathrm{BN}$ method employs the increased values of updated probabilities to identify the most critical event, which may provide incorrect information to risk analysts, leading to incorrect control and preventive measures to control the top event. In this case, the results of dynamic risk analysis studies may be ineffective. To this end, in this study, two criteria, BIM and ROV, were used to identify the important events that have the largest share in the occurrence of the top event. These criteria have been widely used in ranking the basic events leading to the 


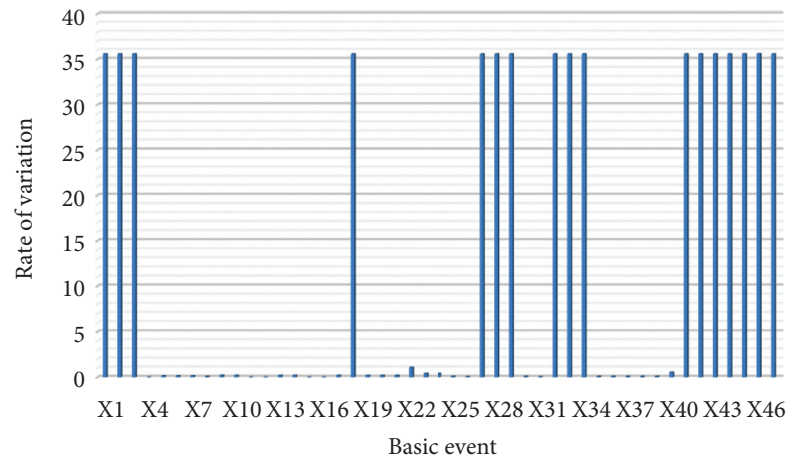

Figure 11: ROV values for basic events.

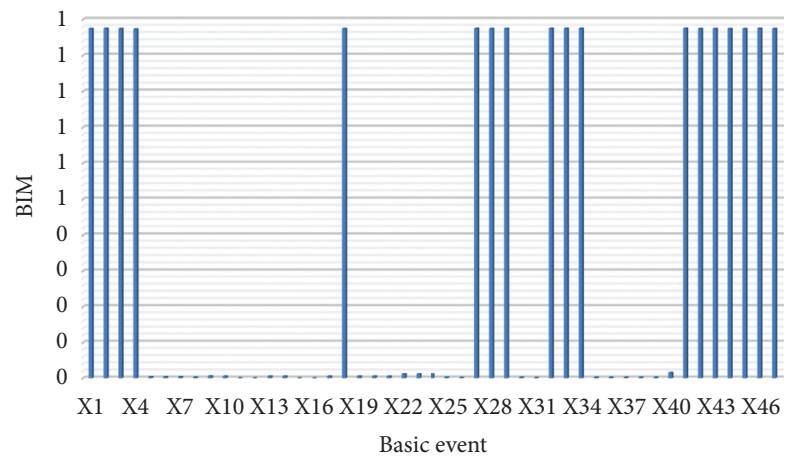

FIgURE 12: BIM values for basic events.

TABLE 6: Effectiveness results of removing the most important MCSs.

\begin{tabular}{lcccc}
\hline & \multicolumn{2}{c}{ BN approach } & \multicolumn{2}{c}{ FT approach } \\
Reliability of TE & Probability of occurrence of TE & Reliability of TE & Probability of occurrence of TE & Control measures \\
\hline 0.9730 & 0.0273 & 0.9490 & 0.05230 & None \\
0.9750 & 0.025312 & 0.9591 & 0.05032 & Removing BE46 \\
0.9750 & 0.025310 & 0.9528 & 0.04834 & Removing BE32 \\
0.9749 & 0.025349 & 0.9527 & 0.04842 & Removing BE27 \\
0.9749 & 0.021282 & 0.9584 & 0.04245 & Removing BE27, BE32, BE46 \\
\hline
\end{tabular}

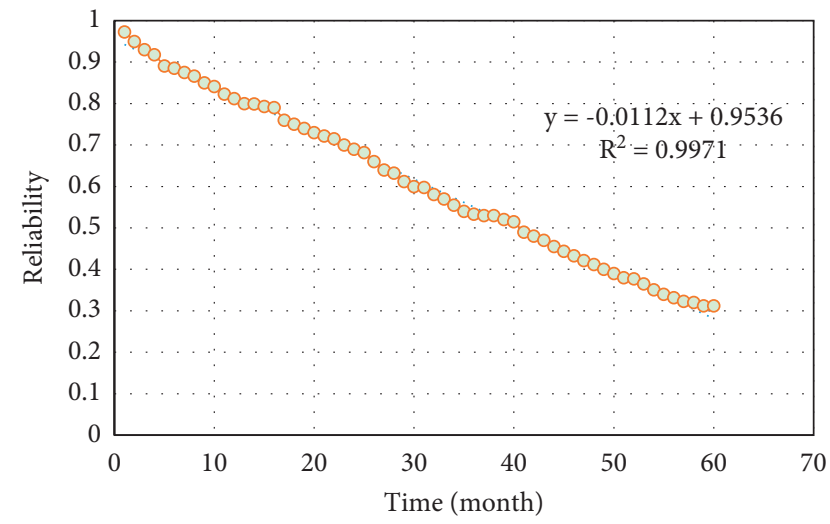

Figure 13: Reliability of overhead cranes over a 5-year period.

occurrence of the top event and sensitivity analysis [68]. Figures 11 and 12 reveal that the highest values of ROV and BIM were observed in X46, X32, X33, X34, X35, and X36 events. This result is correct; since the probability of system failure when these events are not in the state of failure is the lowest among the events, the degree of reliability reduction is the most among the events when these variables are working in a good manner. What is worth mentioning is that the application of the importance measure for both basic events and minimum cut set is twofold: 1- better allocation of resources for control; 2- determining the analysis scope of each of the basic events or minimum cut set. What is often inferred when calculating the degree of importance is that only a small number of events play a more prominent role in the occurrence of the top event; in many cases, only less than $20 \%$ of the events are involved in the occurrence of more than $90 \%$ of the top events. In addition to determining the degree of importance of events, another useful result of this calculation is to clarify the allocation of resources for testing, maintenance, inspection, quality control, etc. Therefore, by optimizing the distribution of resources, costs are minimized and the system is led to a better situation. In addition 
to resource allocation, measuring of importance can be used to determine repair times or decommissioning of parts. The part that plays a major role in the occurrence of the top event must be repaired in less time or taken out of service.

After ranking the root causes, the effect of the corrective actions and the reduction of the probability of the main basic events (assuming the probability of critical basic events is zero) was investigated individually and simultaneously. Table 6 reveals that by removing the most critical event (BE46) the system reliability in the FT approach increased by $1 \%$ (from 0.949 to 0.9591 ) and in the $\mathrm{BN}$ approach the reliability of the system increased by approximately $0.002 \%$ (from 0.973 to 0.975 ). The effect of reducing the three critical events (BE46, BE32, and BE27) was also investigated, indicating that the reliability was $1.009 \%$ in the FT approach and it was approximately $1 \%$ in the $\mathrm{BN}$ approach. The rate of reliability change in the $\mathrm{BN}$ approach was more than that of the FT approach due to the intrinsic characteristics of $\mathrm{BN}$ as a result of considering CCF.

In this study, the Markov chain was used to estimate the reliability of overhead cranes over a 5-year period. Figure 6 shows the reliability predicted by the Markov chain. As can be seen, the reliability of the system decreases over time and its value decreases by $67.9 \%$ after 60 months. This reduction in reliability is due to the presence of effective basic events, such as X46, X32, X33, X34, X35, and X36. These basic events have high variability over time and can reduce the system failure rate over time. According to the results of fault tree analysis to improve the safety performance of processes related to overhead cranes, control measures were proposed with two corrective and preventive approaches in both general and specific areas of cranes. General measures included developing safety checklists for inspecting cranes after repair and maintenance. The most important specific measures included designing and installing a load cell on the crane to prevent overloading and ladle fall, scheduling periodic preventive maintenance using the failed load cell, changing the design of the rope fastener to increase the coefficient and reduce the repair time, and replacing the tow ropes.

\section{Conclusion}

In this study, a method was proposed for analyzing and confirming the reliability of overhead cranes based on Markov chain and fuzzy FT. First, a team consisting of industry and university experts was created to evaluate the validity of the FT, and fuzzy theory was used to determine the failure rate of the probability of root events identified in the qualitative analysis of the FT. The fuzzy FT was drawn in most of the $\mathrm{BN}$, and the reliability of overhead cranes was calculated using the Markov chain for a 5-year period. The results indicated that the method used in this study was successful in predicting the reliability and identifying the effective events in the occurrence of the top event, namely, the ladle fall. In order to reduce the possibility of ladle falls, improve the performance of overhead cranes, and prevent possible accidents, control strategies are suggested, such as proper work instructions, use of proper inspection checklists, and review of work standards to emphasize the inspection of all safety devices and equipment in each shift in cooperation with production and repair units. An important factors in preventing such accidents is how to monitor and support the crane department. The most important limitation of this study was the lack of access to industrial maps of overhead cranes and the lack of documentation related to accidents and quasi-accidents. Although the method presented in this study was used to analyze and evaluate the reliability of overhead cranes for ladle fall scenario, it can be also used to assess the reliability based on other possible scenarios and finally consider multiple scenarios. Dynamic $\mathrm{BN}$ method can be used to analyze the reliability of the whole system.

\section{Data Availability}

The data used to support the findings of this study are included within the article.

\section{Conflicts of Interest}

The authors declare that they have no conflicts of interest.

\section{Acknowledgments}

This work was supported by the Larestan University of Medical Sciences.

\section{References}

[1] O. Sintef, Offshore Reliability Data Handbook, Det Norske Veritas, Høvik, Norway, 2002.

[2] CCPS, Guidelines for Process Equipment Reliability Data, with Data Tables, AIChE, New York, NY, USA, 1989.

[3] F. P. Less, Loss Prevention in the Process Industries: Hazard Identification, Assessment and Control, Butterworth-Heinemann, Oxford, UK, 1980.

[4] The Norwegian Oil Industry Association, Application of IEC 61508 and IEC 61511 in the Norwegian Petroleum Industry, The Norwegian Oil Industry Association, Norway, 2004.

[5] H.-C. Liu, X.-Q. Chen, J.-X. You, and Z. Li, “A new integrated approach for risk evaluation and classification with dynamic expert weights," IEEE Transactions on Reliability, vol. 70, no. 1, pp. 163-174, 2020.

[6] A. S. Cheliyan and S. K. Bhattacharyya, "Fuzzy fault tree analysis of oil and gas leakage in subsea production systems," Journal of Ocean Engineering and Science, vol. 3, no. 1, pp. 38-48, 2018.

[7] Y. Jianxing, C. Haicheng, Y. Yang, and Y. Zhenglong, "A weakest $\mathrm{t}$-norm based fuzzy fault tree approach for leakage risk assessment of submarine pipeline," Journal of Loss Prevention in the Process Industries, vol. 62, Article ID 103968, 2019.

[8] N. Hosseini, S. Givehchi, and R. Maknoon, "Cost-based fire risk assessment in natural gas industry by means of fuzzy FTA and ETA," Journal of Loss Prevention in the Process Industries, vol. 63, Article ID 104025, 2020.

[9] R. Liu, Z. Liu, H.-C. Liu, and H. Shi, "An improved alternative queuing method for occupational health and safety risk assessment and its application to construction excavation," Automation in Construction, vol. 126, Article ID 103672, 2021. 
[10] L. Haarla, U. Pulkkinen, M. Koskinen, and J. Jyrinsalo, “A method for analysing the reliability of a transmission grid," Reliability Engineering \& System Safety, vol. 93, no. 2, pp. 277-287, 2008.

[11] F. A. Rahman, A. Varuttamaseni, M. Kintner-Meyer, and J. C. Lee, "Application of fault tree analysis for customer reliability assessment of a distribution power system," Reliability Engineering \& System Safety, vol. 111, pp. 76-85, 2013.

[12] R. Ferdous, F. Khan, R. Sadiq, P. Amyotte, and B. Veitch, "Fault and event tree analyses for process systems risk analysis: uncertainty handling formulations," Risk Analysis, vol. 31, no. 1, pp. 86-107, 2011.

[13] S. Barua, X. Gao, H. Pasman, and M. S. Mannan, "Bayesian network based dynamic operational risk assessment," Journal of Loss Prevention in the Process Industries, vol. 41, pp. 399410, 2016.

[14] M. Li, D. Wang, and H. Shan, "Risk assessment of mine ignition sources using fuzzy Bayesian network," Process Safety and Environmental Protection, vol. 125, pp. 297-306, 2019.

[15] C. Guo, F. Khan, and S. Imtiaz, "Copula-based Bayesian network model for process system risk assessment," Process Safety and Environmental Protection, vol. 123, pp. 317-326, 2019.

[16] H. J. P. Marvin, Y. Bouzembrak, E. M. Janssen et al., “Application of Bayesian networks for hazard ranking of nanomaterials to support human health risk assessment," Nanotoxicology, vol. 11, no. 1, pp. 123-133, 2017.

[17] M. J. Jafari, M. Pouyakian, A. khanteymoori, and S. M. Hanifi, "Reliability evaluation of fire alarm systems using dynamic Bayesian networks and fuzzy fault tree analysis," Journal of Loss Prevention in the Process Industries, vol. 67, Article ID 104229, 2020.

[18] M. Sýkora, J. Marková, and D. Diamantidis, "Bayesian network application for the risk assessment of existing energy production units," Reliability Engineering \& System Safety, vol. 169, pp. 312-320, 2018.

[19] J. Shi, Y. Zhu, F. Khan, and G. Chen, "Application of Bayesian regularization artificial neural network in explosion risk analysis of fixed offshore platform," Journal of Loss Prevention in the Process Industries, vol. 57, pp. 131-141, 2019.

[20] J. Shi, Y. Chang, F. Khan, Y. Zhu, and G. Chen, "Methodological improvements in the risk analysis of an urban hydrogen fueling station," Journal of Cleaner Production, vol. 257, Article ID 120545, 2020.

[21] Y. F. Li, Y. Liu, T. Huang, H. Z. Huang, and J. Mi, "Reliability assessment for systems suffering common cause failure based on Bayesian networks and proportional hazards model," Quality and Reliability Engineering International, vol. 36, no. 7, pp. 2509-2520, 2020.

[22] A. S. Markowski, M. S. Mannan, and A. Bigoszewska, "Fuzzy logic for process safety analysis," Journal of Loss Prevention in the Process Industries, vol. 22, no. 6, pp. 695-702, 2009.

[23] M. Yazdi, F. Nikfar, and M. Nasrabadi, "Failure probability analysis by employing fuzzy fault tree analysis," International Journal of System Assurance Engineering and Management, vol. 8, no. 2, pp. 1177-1193, 2017.

[24] H. Garg, "A novel approach for analyzing the reliability of series-parallel system using credibility theory and different types of intuitionistic fuzzy numbers," Journal of the Brazilian Society of Mechanical Sciences and Engineering, vol. 38, no. 3, pp. 1021-1035, 2016.

[25] R. Niwas and H. Garg, "An approach for analyzing the reliability and profit of an industrial system based on the cost free warranty policy," Journal of the Brazilian Society of
Mechanical Sciences and Engineering, vol. 40, no. 5, pp. 1-9, 2018.

[26] M. Yazdi, S. Kabir, and M. Walker, "Uncertainty handling in fault tree based risk assessment: state of the art and future perspectives," Process Safety and Environmental Protection, vol. 131, pp. 89-104, 2019.

[27] N. Limnios and G. Oprisan, Semi-Markov Processes and Reliability, Springer Science \& Business Media, Berlin, Germany, 2012.

[28] S. A. Timashev and A. V. Bushinskaya, "Markov approach to early diagnostics, reliability assessment, residual life and optimal maintenance of pipeline systems," Structural Safety, vol. 56, pp. 68-79, 2015.

[29] Q. Li, C. Sun, Z. Huang, X. Xiao, H. Thang, and S. Zhao, "Reliability analysis of Lan Chengyu corroded pipeline with associated defects," Petroleum, vol. 1, no. 3, pp. 244-250, 2015.

[30] C. I. Ossai, B. Boswell, and I. Davies, "Markov chain modelling for time evolution of internal pitting corrosion distribution of oil and gas pipelines," Engineering Failure Analysis, vol. 60, pp. 209-228, 2016.

[31] A. Peiravi, M. A. Ardakan, and E. Zio, "A new Markov-based model for reliability optimization problems with mixed redundancy strategy," Reliability Engineering \& System Safety, vol. 201, Article ID 106987, 2020.

[32] E. E. Lewis and E. E. Lewis, Introduction to Reliability Engineering, vol. 2, Wiley, Hoboken, NJ, USA, 1987.

[33] M. Abdelgawad and A. R. Fayek, "Fuzzy reliability analyzer: quantitative assessment of risk events in the construction industry using fuzzy fault-tree analysis," Journal of Construction Engineering and Management, vol. 137, no. 4, pp. 294-302, 2010.

[34] C. H. Lawshe, "A quantitative approach to content validity," Personnel Psychology, vol. 28, no. 4, pp. 563-575, 1975.

[35] C. Waltz and B. Bausell, Nursing Research: Design Statistics and Computer Analysis, Davis FA, Philadelphia, PA, USA, 1981.

[36] F. Rate, Event Data for Use within Risk Assessments, Health \& Safety Executive Liverpool, Bootle, UK, 2012.

[37] M. Yazdi and S. Kabir, "A fuzzy Bayesian network approach for risk analysis in process industries," Process Safety and Environmental Protection, vol. 111, pp. 507-519, 2017.

[38] N. Ramzali, M. R. M. Lavasani, and J. Ghodousi, "Safety barriers analysis of offshore drilling system by employing fuzzy event tree analysis," Safety Science, vol. 78, pp. 49-59, 2015.

[39] D.-Y. Chang, "Applications of the extent analysis method on fuzzy AHP," European Journal of Operational Research, vol. 95, no. 3, pp. 649-655, 1996.

[40] M. Gul and A. F. Guneri, "A fuzzy multi criteria risk assessment based on decision matrix technique: a case study for aluminum industry," Journal of Loss Prevention in the Process Industries, vol. 40, pp. 89-100, 2016.

[41] M. Yazdi, "Hybrid probabilistic risk assessment using fuzzy FTA and fuzzy AHP in a process industry," Journal of Failure Analysis and Prevention, vol. 17, no. 4, pp. 756-764, 2017.

[42] T. L. Saaty and M. S. Ozdemir, "Why the magic number seven plus or minus two," Mathematical and Computer Modelling, vol. 38, no. 3-4, pp. 233-244, 2003.

[43] H. Nurmi, "Approaches to collective decision making with fuzzy preference relations," Fuzzy Sets and Systems, vol. 6, no. 3, pp. 249-259, 1981.

[44] M. Yazdi and E. Zarei, "Uncertainty handling in the safety risk analysis: an integrated approach based on fuzzy fault tree 
analysis," Journal of Failure Analysis and Prevention, vol. 18, no. 2, pp. 392-404, 2018.

[45] R. Ferdous, F. Khan, R. Sadiq, P. Amyottec, and B. Veitcha, "Analyzing system safety and risks under uncertainty using a bow-tie diagram: an innovative approach," Process Safety and Environmental Protection, vol. 91, no. 1-2, pp. 1-18, 2013.

[46] A. S. Markowski and M. S. Mannan, "Fuzzy risk matrix," Journal of Hazardous Materials, vol. 159, no. 1, pp. 152-157, 2008.

[47] J. J. Buckley, "Fuzzy hierarchical analysis," Fuzzy Sets and Systems, vol. 17, no. 3, pp. 233-247, 1985.

[48] R. Abbassi, F. Khan, N. Khakzad, B. Veitch, and S. Ehlers, "Risk analysis of offshore transportation accident in arctic waters," International Journal of Maritime Engineering, vol. 159, no. A3, pp. A213-A224, 2017.

[49] S.-J. Chen and C.-L. Hwang, Fuzzy Multiple Attribute Decision Making MethodsSpringer, Berlin, Germany, 1992.

[50] T. J. Ross, Fuzzy Logic with Engineering Applications, Vol. 2, Wiley Online Library, Hoboken, NJ, USA, 2004.

[51] S. Akkurt, G. Tayfur, and S. Can, "Fuzzy logic model for the prediction of cement compressive strength," Cement and Concrete Research, vol. 34, no. 8, pp. 1429-1433, 2004.

[52] L. Shi, J. Shuai, and K. Xu, "Fuzzy fault tree assessment based on improved AHP for fire and explosion accidents for steel oil storage tanks," Journal of Hazardous Materials, vol. 278, pp. 529-538, 2014.

[53] R. K. Sharma, D. Kumar, and P. Kumar, "Systematic failure mode effect analysis (FMEA) using fuzzy linguistic modelling," International Journal of Quality \& Reliability Management, vol. 22, no. 9, pp. 986-1004, 2005.

[54] V. R. Renjith, G. Madhu, V. L. Nayagam, and A. B Bhasi, "Two-dimensional fuzzy fault tree analysis for chlorine release from a chlor-alkali industry using expert elicitation," Journal of Hazardous Materials, vol. 183, no. 1-3, pp. 103-110, 2010.

[55] F. V. Jensen, An Introduction to Bayesian Networks, Vol. 210, UCL Press, London, UK, 1996.

[56] T. D. Nielsen and F. V. Jensen, Bayesian Networks and Decision Graphs, Springer Science \& Business Media, Berlin, Germany, 2009.

[57] U. B. Kjaerulff and A. L. Madsen, Bayesian Networks and Influence Diagrams, Vol. 200, Springer Science+ Business Media, Berlin, Germany, 2008.

[58] N. Khakzad, F. Khan, and P. J. P. S. Amyotte, "Dynamic safety analysis of process systems by mapping bow-tie into Bayesian network," Process Safety and Environmental Protection, vol. 91, no. 1-2, pp. 46-53, 2013.

[59] A. Tato, R. Nkambou, J. Brisson, and C. Kenfack, "A Bayesian network for the cognitive diagnosis of deductive reasoning," in Proceedings of the European Conference on Technology Enhanced Learning, Springer, Lyon, France, September 2016.

[60] E. Zarei, A. Azadeh, N. Khakzad, M. M. Aliabadi, and I. Mohammadfam, "Dynamic safety assessment of natural gas stations using Bayesian network," Journal of Hazardous Materials, vol. 321, pp. 830-840, 2017.

[61] R. Khalil Ur, J. Shin, M. Zubair, G. Heo, and H. Son, "Sensitivity study on availability of I\&C components using bayesian network," Science and Technology of Nuclear Installations, vol. 2013, Article ID 656548, 10 pages, 2013.

[62] S. N. Ethier and T. G. Kurtz, Markov Processes: Characterization and Convergence, vol. 282, John Wiley \& Sons, Hoboken, NJ, USA, 2009.

[63] A. Ishikawa, M. Amagasa, T. Shiga, G. Tomizawa, R. Tatsuta, and H. Mieno, "The max-min delphi method and fuzzy delphi method via fuzzy integration," Fuzzy Sets and Systems, vol. 55, no. 3, pp. 241-253, 1993.
[64] M. Omidvari, S. M. R. Lavasani, and S. Mirza, "Presenting of failure probability assessment pattern by FTA in Fuzzy logic (case study: distillation tower unit of oil refinery process)," Journal of Chemical Health and Safety, vol. 21, no. 6, pp. 14-22, 2014.

[65] S. M. Miri Lavasani, Z. Yang, J. Finlay, and J. Wang, "Fuzzy risk assessment of oil and gas offshore wells," Process Safety and Environmental Protection, vol. 89, no. 5, pp. 277-294, 2011.

[66] R. Ferdous, F. Khan, B. Veitch, and P. R. Amyotte, "Methodology for computer aided fuzzy fault tree analysis," Process Safety and Environmental Protection, vol. 87, no. 4, pp. 217226, 2009.

[67] M. J. Jafari, S. Mirza, and M. Omidvari, "The application of Fuzzy logic to determine the failure probability in fault tree risk analysis," Safety promotion and injury prevention (Tehran), vol. 2, no. 2, pp. 113-123, 2014.

[68] F. C. Meng, "Relationships of fussell-vesely and birnbaum importance to structural importance in coherent systems," Reliability Engineering \& System Safety, vol. 67, no. 1, pp. 55-60, 2000. 